
SUBACUTE THYROIDITIS?

Dr. Eda Simsek ${ }^{1}$, Dr. Faruk Yildiz², Dr.Esra Ademoglu ${ }^{3}$, Dr. Senay Arıkan Durmaz ${ }^{4}$, Dr. Murat Filiz², Dr.Fatih Bingol1', Dr.Buket Ozel Bingol'1, Dr.Emine Kartal Baykan², Dr.Ünsal Aydın², Dr. Ahmet Veli Sanibas $^{2}$, Dr. Ayse Carlıoglu²

1- Department of Ear, Nose and Throat, Erzurum Region Education and Research Hospital, Erzurum, Turkey

2- Department of Endocrinology, Erzurum Region Education and Research Hospital, Erzurum, Turkey

3- Department of Endocrinology and Metabolism, Faculty of Medicine, Abant İzet Baysal University, Bolu, Turkey.

4- Department of Endocrinology and Metabolism, Faculty of Medicine, Kırıkkale University, Kırıkkale, Turkey.

\section{INTRODUCTION AND OBJECTIVE:}

Subacute thyroiditis (ST) is a spontaneous remitting inflammatory disease of thyroid gland. Although there is no clear evidence for its specific etiology, multiple factors may responsible for this inflammatory reaction. Mean platelet volume (MPV) is a new important inflammatory marker that indicates disease activity. Aim of this study is to evaluate MPV value in patients with subacute thyroiditis.

\section{PATIENTS AND METHODS:}

Thirty-one patients with ST [mean age $42.55 \pm 11.59$ years; body mass index (BMI) $\left.26.64 \pm 1.33 \mathrm{~kg} / \mathrm{m}^{2}\right]$ and 52 age- and BMI-matched control subjects (mean age $37.34 \pm 17.81$ years, BMl $25.45 \pm 6.76 \mathrm{~kg} / \mathrm{m}^{2}$ ) were evaluated our study. All blood samples in patients with ST were taken at diagnosis. The MPV was measured in a blood sample collected in EDTA. The Beckman Coulter LH 750 (impedance method) analyzer was used for complete blood counts.

\section{RESULTS:}

At diagnosis, the mean FT3 levels were $4.34 \pm 2.86 \mathrm{pg} / \mathrm{mL}$; the mean FT4 levels were $1.61 \pm 1.01 \mathrm{pg} / \mathrm{dL}$; the mean TSH levels in ST were $0.31 \pm 0.35$ $\mu \mathrm{lU} / \mathrm{ml}$ (median 0,16; minimum level 0.001-maximum level $1 \mu \mathrm{lU} / \mathrm{Ml}$ ) whereas in control group, the mean FT3 levels were $4.47 \pm 3.53 \mathrm{pg} / \mathrm{mL}$; the mean FT4 levels were $1.32 \pm 0.65 \mathrm{pg} / \mathrm{dL}$; the mean TSH levels were $1.58 \pm 0.99$ (median 1.3; minimum 0,4-maximum $4.6 \mu \mathrm{lU} / \mathrm{ml}, \mathrm{p}<0.001$ ). ESR in ST group were higher than control group (mean ESR $41.04 \pm 36.19 \mathrm{~mm} /$ hour in ST group vs. $13.24 \pm 13.26 \mathrm{~mm} /$ hour in control group, $p<0.001)$. However, CRP and white blood cell count (WBC) in ST did not find statistically different from control group (mean CRP $5.45 \pm 6.89 \mathrm{mg} / \mathrm{dl}$ vs. $2.06 \pm 1.42 \mathrm{mg} / \mathrm{dl}$, median 3.3 , minimum $0,1-$ maximum $25 \mathrm{mg} / \mathrm{dl}$, and mean WBC $7.51 \pm 1.69$ vs. $7.28 \pm 1.57 / \mu \mathrm{L}$, respectively) despite of higher than their control group.
More importantly, the MPV was significantly higher in the ST group than in their healthy control group $(8.79 \pm 1.23$ and $7.62 \pm 0.75 \mathrm{fL}$, respectively; $p<0.0001)$. MPV had positive correlations between CRP $(r=0.414 ; p=0.013)$ and ESR $(r=0,474 ; p=0,001)$. There was a negative correlation between MPV and TSH $(r=-0,288 ; p=0,017)$.

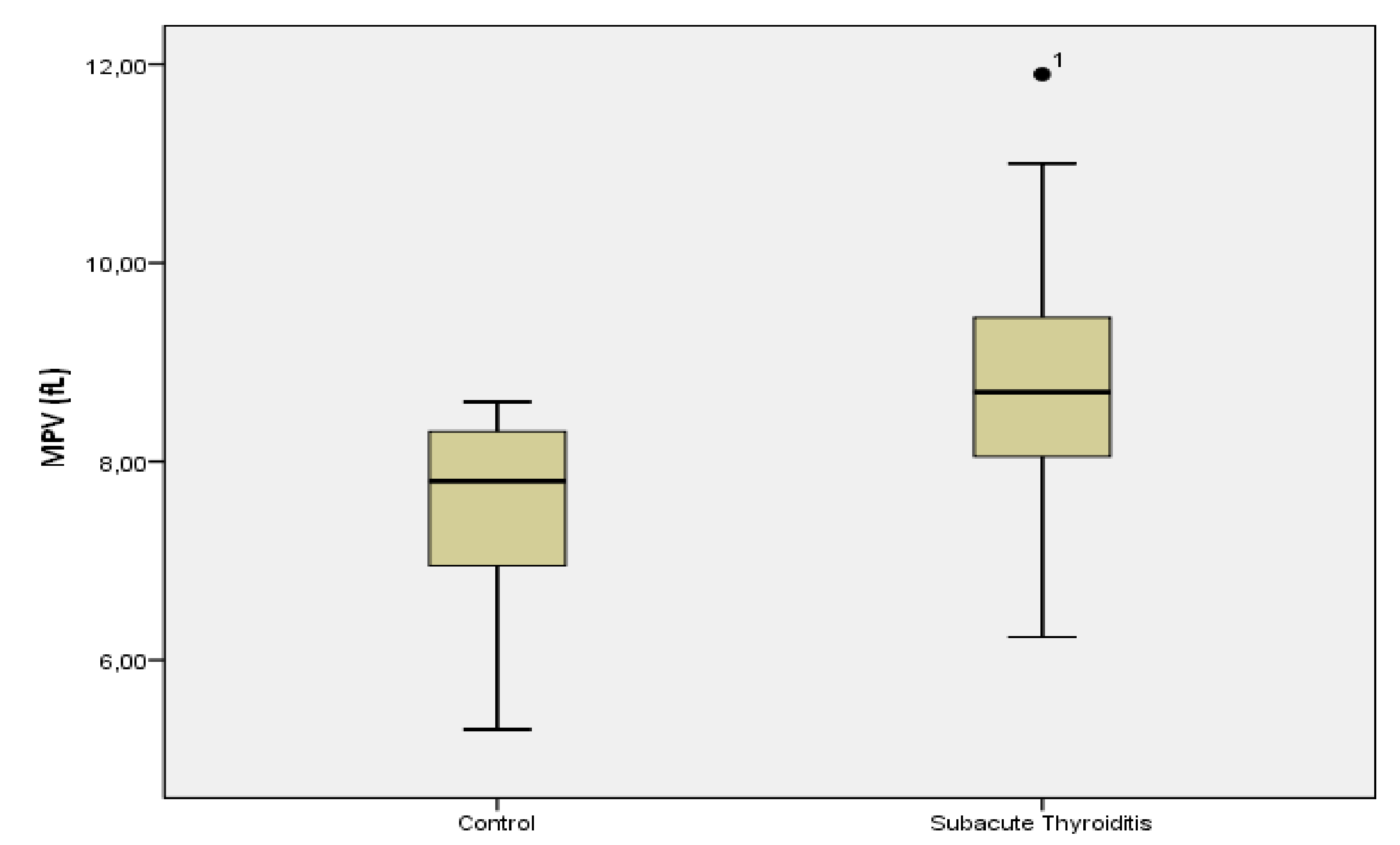

\section{DISCUSSION:}

ST is an inflammatory disease of thyroid gland. MPV is a new important inflammatory marker for disease activity and efficacy of anti-inflammatory treatment in several chronic inflammatory disorders such as inflammatory bowel disease, rheumatoid arthritis and familial Mediterranean fever. According to our knowledge, we demonstrated first time that high MPV value was associated with subacute thyroiditis in hyperthyroid state.

Platelet activation, including MPV, is found that a relationship in the pathophysiology of diseases prone to thrombosis and inflammation. It is well known that an increase in the percentage of large platelets volume leads to increase of MPV levels is observed in inflammatory disease. MPV had positive correlations between CRP $(r=0.414 ; p=0.013)$ and ESR $(r=0.474 ; p=0.001)$.

It is not clear whether elevated MPV volume as a predictive marker of underlying inflammatory environment in ST. Our present study indicate that MPV is an increase in ST patients. Further studies should evaluate exact mechanisms of high MPV levels in ST.

\section{CONCLUCIONS:}

MPV may be a new valuable marker of disease activity of ST as much as high ESR and CRP values. 